\title{
PERBANDINGAN KUALITAS PELUMAS MOTOR 4T DI PALEMBANG DENGAN PARAMETER UJI SPECIFIC GRAVITY, KINEMATIC VISCOSITY, FLASH POINT, POUR POINT, TOTAL ACID NUMBER (TAN) DAN VACUUM DISTILLATION
}

\author{
Dian Kurnia Sari, Nopitasari \\ Program studi Teknik Analisis Laboratorium Migas, Jurusan Teknik Kimia \\ Politeknik Akamigas Palembang
}

\begin{abstract}
Abstrak : Pelumas baik yang berasal dari minyak bumi (mineral oil) atau pelumas sintetik umumnya berupa cairan, yang berfungsi untuk mengurangi gesekan diantara dua benda yang bergerak. Pelumas merupakan bagian yang tak terpisahkan dari mesin. Pelumas dibutuhkan mesin untuk melindungi komponen-komponen mesin dari keausan. Proses pembuatan minyak pelumas adalah distilasi atmosfir, distilasi hampa, deasphalting, solvent extraction, dewaxing, blending dan packaging. Untuk mendapatkan pelumas yang baik perlu ditambahkannya aditif yang sesuai dengan kebutuhan. Aditif adalah senyawa kimia yang bila ditambahkan ke dalam pelumas akan menaikkan unjuk kerja pelumas seperti yang diharapkan. Aditif dapat menentukan mutu pelumas yang digunakan karena dapat merubah sifat kimia maupun sifat fisik dari pelumas. Untuk mengetahui kualitas minyak pelumas diperlukan adanya pengujian sifat fisika dan sifat kimia dari pelumas dengan membandingkan hasil uji dari sampel.
\end{abstract}

Kata Kunci : Pelumas, Deasphalting, Dewaxing, Packaging

\section{Pendahuluan}

Kualitas sistem pelumasan dapat menentukan kinerja mesin, dimana kualitas sistem pelumasan yang baik dapat membuat mesin menjadi lebih awet dan kinerja mesin juga lebih baik. Sebaliknya, kualitas sistem pelumasan yang tidak baik dapat menjadikan mesin menjadi lebih cepat mengalami kerusakan dan kinerja mesin tidak optimal. Pelumasan dapat diartikan sebagai pemberian bahan pelumas pada suatu mesin dengan bertujuan untuk mencegah kontak langsung persinggungan antara permukaan yang bergerak. Pelumasan memiliki suatu peranan yang penting pada suatu mesin dan peralatan yang di dalamnya terdapat suatu komponen yang saling bergesekan yaitu sebagai pengaman agar tidak terjadi kerusakan yang fatal.

Pelumasan memiliki fungsi dan guna yang sangat menentukan panjang pendeknya umur mesin. Fungsi dari pelumasan itu sendiri adalah mengurangi adanya gesekan antara metal dan komponen-komponen mesin lainnya sehingga dapat meminimalkan resiko terjadinya kerusakan pada mesin. Sedangkan pelumasan berguna untuk mencegah atau mengurangi terjadinya keausan pada komponen-komponen mesin yang saling bergesekan. Sistem pelumasan berguna untuk melumasi bagian-bagian yang bergeser satu sama lainnya. Tempat pergeseran tersebut tidak halus, tetapi ada kekasaran atau benjolan (terlihat dengan loupe), maka perlu pelumasan. Dengan adanya minyak pelumas, maka yang terjadi nantinya adalah pergeseran antara minyak pelumas dengan logam. Minyak pelumas harus mempunyai sifat-sifat tertentu, agar tetap eksis ketika pergeseran terjadi, sehingga memungkinkan terjadi pelumasan yang sebaik-baiknya.

Pelumas merupakan bagian yang tak terpisahkan dari mesin. Pelumas dibutuhkan mesin untuk melindungi komponenkomponen mesin dari keausan. Prinsip dasar dari pelumasan adalah mencegah terjadinya solid friction atau gesekan antara dua permukaan logam yang bergerak, sehingga gerakan dari masing-masing logam dapat lancar tanpa banyak energi yang terbuang. Sifat dari pelumas adalah sebagai pelindung mesin dari keausan, pelumas juga dituntut seperti viskositas yang sesuai, pour point yang rendah, volatilitas rendah, stabil terhadap panas dan oksidasi, 
serta indeks viskositas yang tinggi. Banyaknya pelumas yang dipasarkan kepada masyarakat bisa menjadi tolak ukur untuk kita ketahui apakah produk pelumas yang dipasarkan memenuhi nilai pelumas yang sesuai dengan spesifikasi atau tidak. Maka dari itu pada laporan ini akan dibahas mengenai perbedaan kualitas pelumas yang dipasarkan pada bengkel resmi dan non resmi. Yang dianggap kategori resmi adalah tempat atau kios yang mempunyai izin pendistribusian produk pelumas dengan merk tertentu (dealer resmi atau tempat yang ada penjualan motor, oli, sparepart, dan melayani service). Yang dianggap kategori non resmi adalah bengkel-bengkel kecil yang melayani service dan menjual oli.

\section{Dasar Teori}

\subsection{Pelumas}

Pelumas baik yang berasal dari minyak bumi (mineral oil) atau pelumas sintetik umumnya berupa cairan, yang berfungsi untuk mengurangi gesekan diantara dua benda yang bergerak. Pelumas berfungsi sebagai lapisan pelindung yang memisahkan dua permukaan yang berhubungan. Minyak pelumas mempunyai kekentalan yang berbeda-beda, kekentalan (viskositas) pelumas diklasifikasikan secara khusus oleh International Organization for Standardization (ISO). Pada suhu mesin yang tinggi kekentalan oli cenderung turun dan oli mengalami pemuaian volume, sebaliknya bila suhu mesin rendah maka kekentalan oli cenderung meningkat, dan oli mengalami penyusutan volume. Oli mengalami perubahan volume bila terjadi perubahan temperatur, volume suatu zat berhubungan dengan besarnya massa jenis zat tersebut. Jika volume bergantung pada temperatur, maka massa jenis juga bergantung pada temperatur.

Dari beberapa faktor diatas, temperatur minyak pelumas sangat berperan penting dalam sebuah pelumasan pada mesin, karena apabila temperatur minyak pelumas yang terlalu tinggi akan mengakibatkan kurangnya efisiensi dari pelumasan tersebut. Adapun temperatur normal pelumasan yaitu $45^{\circ} \mathrm{C}$ $50^{\circ} \mathrm{C}$ dan temperatur tidak normalnya $50^{\circ} \mathrm{C}$ -
$70{ }^{\circ} \mathrm{C}$. Naiknya temperatur minyak lumas dapat disebabkan oleh beberapa hal, seperti kurangnya penyerapan panas pada lubricating oil cooler dan hal ini dapat disebabkan oleh beberapa faktor seperti terjadinya penyumbatan pada pipa-pipa kapiler pada lubricating oil cooler serta dapat juga disebabkan oleh volume media pendingin yang masuk ke lubricating oil cooler tidak sebanding dengan minyak lumas yang di dinginkan.

Selain hal diatas temperatur media pendingin yang terlalu tinggi juga dapat menyebabkan naiknya temperatur minyak lumas, adapun faktor-faktor lain yang dapat menyebabkan naiknya temperatur minyak lumas seperti terjadinya kebocoran pembakaran yang masuk ke crank case, serta pemakaian minyak lumas yang sudah melebihi jam kerja atau minyak lumas yang sudah tidak layak pakai akan mengalami kenaikan temperatur dengan cepat jika terusmenerus di gunakan. Untuk itu pada sistem pelumasan merupakan suatu hal yang sangat penting untuk menjaga temperatur dari minyak lumas, sehingga tercipta pelumasan yang lebih efisien dan komponen mesin yang bergerak tidak tejadi kerusakan serta mesin dapat beroperasi lebih lama.

\subsection{Aditif yang terkandung pada pelumas}

Aditif adalah senyawa kimia yang bila ditambahkan ke dalam pelumas akan menaikkan unjuk kerja pelumas seperti yang diharapkan. Aditif ini dapat menentukan mutu pelumas yang digunakan karena ia dapat merubah sifat kimia maupun sifat fisik dari pelumas. Tujuan menggunakan aditif untuk mem-blending pelumas yaitu untuk melindungi atau memperbaiki mutu pelumas terhadap perubahan sifat kimia atau penurunan mutu pelumas, melindungi kerusakan mesin terhadap produk-produk hasil pembakaran dan untuk memperbaiki sifat suatu pelumas. Atau memberikan sifat baru terhadap pelumas yang sesuai dengan penggunaannya. Aditif dapat terdiri dari unsur-unsur kimia seperti barium, calsium, phosphorus, sulfur, chlorine, zinc, lead, polymer dan sebagainya. Komposisi antara 
satu aditif dengan lainnya harus dapat digabungkan sebaik mungkin dalam satu formasi tertentu. Hal ini berkaitan dengan pesatnya perubahan pada rancang bangun mesin serta tuntutan kerja mesin yang meningkat.

\subsection{Aditif Utama}

\section{Antioxidant}

Kebanyakan di dalam lingkungan kerja terjadi kontak antara minyak pelumas dengan udara yang beroperasi pada suhu tinggi. Juga dengan logam atau bahan kimia lain yang berlaku sebagai pro-oxidant atau katalisator oksidasi. Dalam situasi seperti ini minyak pelumas baik yang berbahan dasar mineral atau sintetis ester akan mengalami sederetan reaksi oksidasi yang kompleks. Hasil oksidasi yang paling merugikan adalah menurunnya viskositas minyak pelumas yang berarti menunjukkan kenaikan kontaminasi asam seperti petroleum oxyacid dan pembentukan bahan-bahan yang bersifat karbon. Oksidasi minyak pelumas melibatkan reaksi berantai yang mula-mula membentuk peroksida organik kemudian bereaksi dengan minyak pelumas yang belum teroksidasi dan selanjutnya bereaksi dengan oksigen dari udara untuk membentuk asam yang korosif. Untuk itu ditambahkan aditif antioksidan yang berfungsi untuk mengurangi peroksida yang kemudian akan dapat menghentikan reaksi berantai yang terjadi. Bahan kimia yang biasa digunakan sebagai antioksidan adalah sulfida, disulfida, fosfit amina, dan fenol.

\section{Antiwear / Extreme Pressure}

Adalah bahan kimia yang ditambahkan pada minyak pelumas dengan maksud untuk menghindari kerusakan atau keausan akibat kontak logam dengan logam pada permukaan yang bergerak.

\section{Anticorrosive}

Adalah bahan kimia yang digunakan untuk melindungi komponen metal non ferroua (bukan besi) yang mudah terkena korosi pada mesin. Aditif yang biasa digunakan adalah logam ditiofosfat, logam ditiokarbamat, sulfurized terpene, sulfurized dipentene, phosphorus pentasulfide.

\section{Antirust}

Adalah bahan yang digunakan untuk melindungi permukaan logam besi terhadap timbulnya karat.

\section{Pour Point Depressant}

Adalah bahan kimia yang ditambahkan dengan harapan akan membuat pour point menjadi lebih rendah. Bahan kimia yang biasa digunakan adalah polimer organik seperti polimetakrilat, poliakrilamida atau juga beberapa monomer seperti tetrasilikat, fenil tristeariloksilen dan pentaeritritol tetrastearat.

\section{Detergent}

Merupakan suatu aditif dalam bentuk ikatan kimia yang memberikan kemampuan menghindari atau mengurangi timbulnya deposit / endapan dari ruang bakar maupun dari bagian mesin lainnya dimana mesin beroperasi pada suhu tinggi. Bahan yang sering digunakan adalah alumunium naftenat, kalsium diklorostearat, kalsium fenilklorostearat, dan kalsium klorostearat.

\section{Dispersant}

Aditif yang bekerja untuk menghalangi timbulnya lumpur dan menghalangi terbentuknya deposit pada suhu rendah (biasanya digunakan untuk minyak pelumas pada kendaraan yang berhenti dan berjalan berulang-ulang. Bahan kimia yang sering digunakan adalah alkil metakrilat, dialkil aminoetil metakrilat, polistearamida.

\section{Metodologi}

\section{a. Waktu dan Tempat}

Pelaksanaan Penelitian dilakukan pada bulan April - Mei 2016 di laboratorium AFR Politeknik Akamigas Palembang, dengan sampel pelumas yang diambil pada toko kecil dan bengkel resmi.

b. Metode

ASTM D 445, untuk pengujian Kinematic Viscosity.

ASTM D 92, untuk pengujian Flash Point COC.

ASTM D 97, untuk pengujian Pour Point.

ASTM D 1298, untuk pengujian Specific Gravity.

ASTM D 974, untuk pengujian Total Acid Number (TAN). 
Hasil Analisa Pengujian Minyak Pelumas

Tabel 4.1 Hasil Analisa Sampel Minyak pelumas Jenis "Yamalube 10W - 40"

\begin{tabular}{|c|c|c|c|c|c|c|c|}
\hline \multirow{2}{*}{ No. } & \multirow{2}{*}{ Karakteristik } & Metode & \multirow{2}{*}{ Unit } & \multicolumn{2}{|c|}{ Batasan } & \multicolumn{2}{|c|}{ Hasil } \\
\hline & & ASTM & & Min & $\operatorname{Max}$ & Resmi & Eceran \\
\hline 1 & $\begin{array}{c}\text { Kinematic } \\
\text { Viscosity }\end{array}$ & D 445 & $\mathrm{cSt}$ & \multicolumn{2}{|c|}{ Sesuai SAE } & 14,8 & 14,4 \\
\hline 2 & Flash Point COC & D 92 & ${ }^{\circ} \mathrm{C}$ & 200,0 & - & 227 & 227 \\
\hline 3 & Pour Point & D 97 & ${ }^{\circ} \mathrm{C}$ & - & - & -28 & -28 \\
\hline 4 & Specific Gravity & D 1298 & - & - & - & 0,8667 & 0,8651 \\
\hline 5 & $\begin{array}{c}\text { Total Acid } \\
\text { Number }(\text { TAN })\end{array}$ & D 664 & $\begin{array}{c}\mathrm{mg} \\
\mathrm{KOH} / \mathrm{g}\end{array}$ & - & - & 1,2 & 1,2 \\
\hline
\end{tabular}

Tabel 4.2 Hasil Analisa Sampel Minyak pelumas Jenis "Top1 10W - 40"

\begin{tabular}{|c|c|c|c|c|c|c|c|}
\hline \multirow{2}{*}{ No. } & \multirow{2}{*}{ Karakteristik } & Metode & \multirow{2}{*}{ Unit } & \multicolumn{2}{|c|}{ Batasan } & \multicolumn{2}{|c|}{ Hasil } \\
\hline & & ASTM & & Min & Max & Resmi & Eceran \\
\hline 1 & $\begin{array}{c}\text { Kinematic } \\
\text { Viscosity }\end{array}$ & D 445 & $\mathrm{cSt}$ & \multicolumn{2}{|c|}{ Sesuai SAE } & 13.7 & 13.2 \\
\hline 2 & Flash Point COC & D 92 & ${ }^{\circ} \mathrm{C}$ & 200.0 & - & 221 & 221 \\
\hline 3 & Pour Point & D 97 & ${ }^{\circ} \mathrm{C}$ & - & - & -22 & -22 \\
\hline 4 & Specific Gravity & D 1298 & - & - & - & 0.88670 & 0.8670 \\
\hline 5 & $\begin{array}{c}\text { Total Acid } \\
\text { Number }(\text { TAN })\end{array}$ & D 664 & $\begin{array}{c}\mathrm{mg} \\
\mathrm{KOH} / \mathrm{g}\end{array}$ & - & - & 1.3 & 1.3 \\
\hline
\end{tabular}

\subsection{Pembahasan}

\subsubsection{Kinematic Viscosity}

Hasil yang diperoleh pada pengujian Viskositas Kinematik (Kinematic Viscosity) minyak pelumas jenis "Yamalube 10W - 40" dari kios resmi (agen) adalah $14,8 \mathrm{cSt}$ dan dari kios eceran adalah 14,4 cSt, sedangkan untuk minyak pelumas jenis "Top1 10W - 40" dari kios resmi (agen) adalah 13,7 cSt dan dari kios eceran adalah 13,2 cSt. Hal tersebut menujukkan bahwa kedua jenis sampel pelumas memenuhi spesifikasi berdasarkan kekentalan menurut SAE, nilai viskositas (cSt) pada $100{ }^{\circ} \mathrm{C}$ ASTM D 445 .

Tabel 4.3 Klasifikasi berdasarkan kekentalan menurut SAE, Nilai Viskositas (cSt) Pada $100{ }^{\circ}$ C ASTM D 445

\begin{tabular}{|c|c|c|}
\hline SAE & Minimum & Maksimum \\
\hline $0 \mathrm{~W}$ & 3,8 & - \\
\hline $5 \mathrm{~W}$ & 3,8 & - \\
\hline $10 \mathrm{~W}$ & 4,1 & - \\
\hline $15 \mathrm{~W}$ & 5,6 & - \\
\hline $20 \mathrm{~W}$ & 5,6 & - \\
\hline $25 \mathrm{~W}$ & 9,3 & - \\
\hline 20 & 5,6 & 9,3 \\
\hline 30 & 9,3 & 12,5 \\
\hline
\end{tabular}




\begin{tabular}{|c|c|c|}
\hline SAE & Minimum & Maksimum \\
\hline 40 & 12,5 & 16,3 \\
\hline 50 & 16,3 & 21,9 \\
\hline 60 & 21,9 & 26,1 \\
\hline
\end{tabular}

Keterangan : $\mathrm{W}=$ Winter

Berdasarkan data diatas bahwa kedua jenis pelumas yang berasal dari kios resmi (agen) dan kios ececran memiliki sedikit perbedaan yakni nilai viskositas sampel dari kios resmi (agen) lebih tinggi dari pada nilai sampel dari kios eceran. Hal ini dapat dipengaruhi oleh adanya perubahan suhu (kenaikan suhu) pada saat penyimpanan sampel pelumas tersebut yang menyebabkan sampel pelumas menjadi encer dan laju alir yang dihasilkan semakin cepat, maka nilai viskositas yang didapat semakin kecil (rendah). Semakin tinggi nilai viskositas suatu sampel pelumas maka semakin bagus kualitas dari sampel pelumas tersebut karena semakin kental minyak maka laju aliran dekat permukaan akan semakin lambat atau gaya geser antara minyak dan permukaan makin besar.

\subsubsection{Flash Point COC}

Hasil yang diperoleh pada pengujian flash point COC minyak pelumas jenis "Yamalube $10 \mathrm{~W}-40$ " dari kios resmi (agen) adalah $227{ }^{\circ} \mathrm{C}$ dan dari kios eceran adalah $227{ }^{\circ} \mathrm{C}$, sedangkan untuk minyak pelumas jenis "Top1 10W 40 " dari kios resmi (agen) adalah $221{ }^{\circ} \mathrm{C}$ dan dari kios eceran adalah $221{ }^{\circ} \mathrm{C}$. Hal tersebut menujukkan bahwa kedua jenis sampel pelumas memenuhi spesifikasi berdasarkan SK Dirjen Migas No. 85 K/34/DDJM/1998 tanggal 24 Agustus 1998, yaitu minimum $200,0{ }^{\circ} \mathrm{C}$.

Berdasarkan data diatas bahwa kedua jenis sampel pelumas tidak ada perbedaan nilai flash point (titik nyala) diantara kedua jenis sampel tersebut. Dimana nilai flash point (titik nyala) didapatkan dari suhu (temperatur) terendah pada waktu pemanasan api pencoba yang menyebabkan uap (gas) yang berada dipermukaan contoh (sampel) menyala sekejap. Apabila suhu titik nyala sampel- kurang dari $200{ }^{\circ} \mathrm{C}$ dikhawatirkan bahan bakar sampel tersebut dapat mudah terbakar pada suhu ruang sehingga membahayakan keselamatan selama pengangkutan dan penyimpanan.

\subsubsection{Pour Point}

Hasil yang diperoleh pada pengujian pour point minyak pelumas jenis "Yamalube 10W - 40" dari kios resmi (agen) adalah $-28{ }^{\circ} \mathrm{C}$ dan dari kios eceran adalah $-28{ }^{\circ} \mathrm{C}$, sedangkan untuk minyak pelumas jenis "Top1 10W - 40" dari kios resmi (agen) adalah $-22{ }^{\circ} \mathrm{C}$ dan dari kios eceran adalah $-22{ }^{\circ} \mathrm{C}$. Hal tersebut menujukkan bahwa kedua jenis sampel pelumas memenuhi spesifikasi, karena pada umumnya jika hasil yang didapatkan dibawah $0{ }^{\circ} \mathrm{C}$, maka sampel pelumas tersebut dapat dikatakan nilai pour point nya bagus.

Berdasarkan data diatas bahwa kedua jenis sampel pelumas tersebut memiliki nilai pour point yang sama yakni dibawah suhu $0{ }^{\circ} \mathrm{C}$. Pour point (titik tuang) merupakan sifat kritis dari pelumas, sebab minyak pelumas harus tetap encer dan dapat memenuhi fungsinya pada suhu rendah selama suhu operasi maupun suhu lingkungan. Sehingga pour point pelumas harus lebih rendah dari suhu tersebut agar tetap dapat mengalir.

\subsubsection{Specific Gravity}

Hasil yang diperoleh pada pengujian specific gravity minyak pelumas jenis "Yamalube 10W - 40" dari kios resmi (agen) adalah 0,8667 dan dari kios eceran adalah 0,8651 , sedangkan untuk minyak pelumas jenis "Top1 10W - 40" dari kios resmi (agen) adalah 0,8670 dan dari kios eceran adalah 0,8670. Hal tersebut menujukkan bahwa kedua jenis sampel pelumas memenuhi spesifikasi, karena- pada umumnya nilai specific gravity pelumas adalah kurang dari 
1(satu). Pelumas dengan berat jenis yang tinggi mengandung lebih banyak energi per galon (heating value). Apabila nilai SG yang diperoleh melebihi batas maksimum maka mengakibatkan peningkatan deposite pada mesin dan asap sehingga dapat mengganggu kinerja mesin.

\subsubsection{Total Acid Number (TAN)}

Hasil yang diperoleh pada pengujian Total Acid Number (TAN) minyak pelumas jenis "Yamalube $10 \mathrm{~W}$ 40" dari kios resmi (agen) adalah 1,2 mg $\mathrm{KOH} / \mathrm{g}$ dan dari kios eceran adalah adalah $1,2 \mathrm{mg} \mathrm{KOH} / \mathrm{g}$, sedangkan untuk minyak pelumas jenis "Top1 10W - 40" dari kios resmi (agen) adalah adalah 1,3 $\mathrm{mg} \mathrm{KOH} / \mathrm{g}$ dan dari kios eceran adalah adalah 1,3 mg $\mathrm{KOH} / \mathrm{g}$. Hal tersebut menujukkan bahwa kedua jenis sampel pelumas memenuhi spesifikasi, karena dalam pengujian TAN ini diharapkan nilai yang didapatkan harus sekecil-kecilnya maka dari itu, jika nilai TAN tinggi akan menimbulkan korosi yang banyak pada mesin bahan bakar dan akan merusak mesin. Sampel pelumas yang di uji adalah sampel pelumas baru, jadi kandungan TAN didalam pelumas kecil karena belum teroksidasi oleh uap air dan salah satu sifat dari pelumas adalah tahan terhadap oksidasi.

\section{Kesimpulan}

1. Dari hasil pengujian pelumas dari kios resmi (agen) dan kios eceran berdasarkan parameter uji Kinematic Viscosity, Flash Point COC, Pour Point, Specific Gravity, dan Total Acid Number (TAN), maka kualitas dan karakteristik sampel pelumas tersebut layak untuk digunakan.

2. Dari kelima parameter uji, pengujian Kinematic Viscosity yang memiliki berbedaan hasil, akan tetapi perbedaan tersebut tidak begitu jauh sehingga tidak mempengaruhi parameter uji yang lain nya.

3. Faktor yang dapat mempengaruhi perbedaan hasil pengujian diantara kedua sampel pelumas dari kios resmi (agen) dan kios eceran adalah adanya perubahan suhu pada saat penyimpanan sehingga mempengaruhi hasil dari pengujian Kinematic Viscosity.

\section{DAFTAR PUSTAKA}

American Society for Testing and Materials ASTM D-86. 2012. Standard Test Method for Distilation of Petroleum products at Atmospheric Pressure. Philadelphia : ASTM International.

Bal, Florensia J. De A. M. 2016. Evaluasi Minyak Bumi Berdasarkan Distilasi True Boiling Point (TBP) dan Hempel di PPTMGB Lemigas. Politeknik Akamigas Balongan Indramayu : "Tugas Akhir Tidak Diterbitkan".

Ginting, Jadinta., et al. 2014. "Evaluasi Proses Pembuatan Avtur (Aviation Turbine) Berdasarkan Analisa Sifat Fisik dan Kimia Minyak Mentah (Crude Oil) di PT Pertamina RU II Dumai”. Jurnal Ilmu Teknik. 2 (3), hlm. 2338-7459.

Hafiz, Said. 2006. Evaluasi Minyak Mentah Lalang Sebagai Bahan Baku Pada Kilang Pengolahan Minyak Bumi. Universitas Sriwijaya : "Tugas Akhir Tidak Diterbitkan".

Hardjono, A. 2001. Teknologi Minyak Bumi. Yogyakarta : Universitas Gajah Mada.

Jonathan, Sarwono. 2006. Metode Penelitian Kuantitatif dan Kualitatif. Yogyakarta : Graha Ilmu.

Keputusan Direktur Jendral Minyak dan Gas Bumi. 1979. Bahan Bakar Jet (AVTUR) No. 002/P/MD/Migas/1979. Jakarta : Direktur Jendral Minyak dan Gas Bumi.

Keputusan Direktur Jendral Minyak dan Gas Bumi. 1990. Bahan Bakar kerosin No. 
17.K/72/DJM/1999 Tanggal 16 April 1999. Jakarta : Direktur Jendral Minyak dan Gas Bumi.

Matnuri. 2003. Kertas Kerja Wajib "Evaluasi Minyak Bumi Jene Sebagai Bahan Baku Kerosine dengan Distilasi Sibata". Cepu : STEM AKAMIGAS.

Syahrizal. 2015. Diktat Minyak Bumi dan Produk. Politeknik Akamigas Palembang : "Diktat Tidak Diterbitkan".
The Institute of Petroleum 170. 1965. Determination of Denstiy or Relative Density of Petroleum Product by Pycnometer. London : The institute of Petroleum.

The Institute of Petroleum 170. 2007. Petroleum Products and Other Liquids Determination of Flash point (Abel Closed Cup Methode). London : The institute of Petroleum. 